\title{
Lessons learnt from a participatory integrated assessment of greenhouse gas emission reduction options in firms
}

\author{
Serge I. P. Stalpers · André R. van Amstel • \\ Rob B. Dellink · Ivo Mulder · Saskia E. Werners • \\ Carolien Kroeze
}

Received: 7 June 2006/Accepted: 5 May 2007/Published online: 8 June 2007

(C) Springer Science+Business Media B.V. 2007

\begin{abstract}
This article discusses an approach for identification and evaluation of shortterm greenhouse gas (GHG) emission reduction options in firms. The approach is based on lessons learnt from a project using Participatory Integrated Assessment (PIA) and builds on the idea that effective public climate policy for firms requires options that have support from stakeholders and are practically feasible. Scenarios are used to provide a link with short-term policy developments and a model assists to communicate quantitative effects of options to participating stakeholders. Our approach can be seen as a first step towards a framework that meets the need for more systematic approaches to PIAs identifying effective public policies for short-term GHG emission reduction options in firms. In order to identify effective options for non-carbon dioxide GHG emission reductions, our approach has been applied to Dutch dairy farms, after which it has been refined. The case study suggests that our approach can provide balance between practical, context specific issues and scientific-theoretical aspects, thereby avoiding common pitfalls of participatory research projects to focus too much on either theory or practical issues.
\end{abstract}

Keywords Participatory integrated assessment - Climate change policy · Stakeholder involvement $\cdot$ Methodology $\cdot$ Agriculture

\footnotetext{
S. I. P. Stalpers $(\bowtie) \cdot$ A. R. van Amstel · I. Mulder · C. Kroeze Environmental Systems Analysis Group, Wageningen University, P.O. Box 47, 6700 AA Wageningen, The Netherlands

e-mail: Serge.Stalpers@wur.nl

R. B. Dellink

Environmental Economics and Natural Resources Group, Wageningen University,

Hollandseweg 1, $6706 \mathrm{KN}$ Wageningen, The Netherlands

S. E. Werners

Centre for Water and Climate, Alterra, Wageningen UR, P.O. Box 47, 6700 AA Wageningen, The Netherlands
} 


\section{Introduction}

In the 1980s and 1990s global climate policy debated the need for greenhouse gas (GHG) emission reductions and negotiated national emission targets. Now that agreements have been made on emission targets in the United Nations Framework Convention on Climate Change (FCCC) Kyoto Protocol, the attention of climate policy has shifted to the more practical issue of meeting those targets through implementation. In most countries the attention has been directed to implementation of promising emission reduction options at the local and short-term scale, because implementation ultimately occurs at the local scale, and the approach of the first commitment period of the Kyoto Protocol, in 2008-2012, makes short-term action necessary. In the Netherlands, for example, the Netherlands Research Program on Climatic Change (NRP-CC) explores GHG emission reduction options for different economic sectors. In such programs many options to reduce GHG emissions have been identified. Greenhouse gasses are to a considerable extent emitted by production sectors, for instance industry and agriculture, and therefore it is worthwhile to investigate abatement options that can be taken by firms.

Effective firm-level options may be identified by evaluating options using participatory methods that involve stakeholders in the assessment process. Participation has several advantages. Participation at the local level has been shown to increase efficiency because, inter alia, it can achieve "better choices for and identification of possibilities and opportunities in local systems" (Hedger et al. 2000, p. 116). Policy strategies formulated in a top-down mode, without consultation with stakeholders, risk failure in the implementation phase because local conditions need to be taken into account (Lin et al. 2000).

When identifying and evaluating options for firm-level policy it is important to (1) take into account practical feasibility, i.e., to ensure that options that have high technical potential in theory can also be implemented in practice. This requires participation of stakeholders from the firm, or from a representative sample of firms in a sector, to provide the details of the production process. In addition, it is important to (2) take into account support from firm management (whom we will later refer to as 'primary stakeholders'), i.e., to ensure that the options are perceived by stakeholders as being legitimate so that they will not obstruct implementation. This requires participation of stakeholders from the firm so that the values and perceptions of stakeholders can be taken into account.

Considerable progress has been made in developing and applying participatory methods. Many Participatory Integrated Assessments (PIAs) have been performed illustrating the use of stakeholder knowledge, values and perceptions (e.g., Darier et al. 1998; Behringer et al. 2000; Rotmans et al. 2000; Hare and Pahl-Wostl 2002; Tansey et al. 2002; Tuinstra et al. 2002; Pahl-Wostl and Hare 2004). Despite the progress made, these studies still typically use an ad-hoc PIA approach for dealing with local and short-term environmental policy: the methodological design is not defined from the start but rather takes form and evolves as the project proceeds, and lack a systematic methodological approach for combining existing PIA methods. A systematic framework has been proposed for adaptation to global change (Schröter et al. 2005). To our knowledge, no such systematic framework for emission reduction options has been reported in the literature.

There are two reasons why a systematic framework for emission reduction options would be useful. Firstly, a common pitfall of ad-hoc approaches is to focus too much either on results (getting the job done without rigorous application of methodology; Glicken 2000; Van Asselt and Rijkens-Klomp 2002) or on scientific aspects (which in the extreme case leads to participants being trapped in a scientific experiment of which the only 
purpose is to test a method). In contrast, using a systematic framework allows for a systematic application of methods, thereby providing balance between scientific and practical aspects. Secondly, once a systematic framework is developed, it can be applied and validated on different cases and improved upon, thereby setting the stage for further advances in the development of participatory methodology. Due to the context dependency of participatory methods it is not possible to design a generic systematic PIA framework for all environmental issues (Van de Kerkhof 2004). It may, however, be possible to devise a systematic PIA framework for a specific set of environmental issues, such as GHG emission reduction in firms.

The purpose of this article is to present a PIA approach that could function as a basis for the development of a systematic PIA framework. The approach addresses the need to develop combinations of existing PIA methods which help identify effective public policies for short-term, local GHG emission reduction options for implementation during the first Kyoto Protocol commitment period. Our approach is based on the combination of the use of scientific tools, including scenarios and stylized models, with the use of stakeholder knowledge, taking into account stakeholder values and perceptions. The approach also allows for an assessment of the practical feasibility of and support from firm management for emission reduction options. Though it is clear from the discussion above that many problems need to be resolved before a generic systematic framework can be developed, our approach provides a first step towards this goal by explicitly addressing the balance between practical and scientific aspects.

A preliminary version of the approach has been applied to a case study which focuses on GHG emission reduction in firms in the agricultural sector in the Netherlands. Together, the approach and case study show that common pitfalls, such as a focus only on practical or scientific-theoretical aspects, can be avoided.

\section{Towards a systematic PIA approach}

This section presents an approach for PIAs identifying effective public policies for shortterm GHG emission reduction options in firms. First, criteria for such an approach are derived from (i) the premise that practical feasibility of and support from firm management are prerequisites for effective firm-level policy, (ii) scientific tools and insights that can be exploited to facilitate the discussions with stakeholders, and (iii) taking into account the characteristics of the climate change problem from the perspective of firms. Subsequently an outline of the approach is given, after which the purpose, roles of participants and methods for each task in the approach are presented.

\subsection{Criteria for the approach}

In this study we consider that effective firm-level climate policy, i.e., policy that has a better chance of implementation in the short-term, requires emission reduction options that:

(1) are environmentally effective,

(2) are cost-efficient for the firms involved,

(3) are practically feasible in the context of the daily routine of firms or can be made so within a short time-span, and

(4) have the support from firm management. 
An Integrated Assessment (IA) for identifying successful policy options preferably takes into account these four aspects. Following Rotmans we interpret IA as "a structured process of dealing with complex issues, using knowledge from various scientific disciplines and/or stakeholders, such that integrated insights are made available to decision makers" (Rotmans 1998, p. 155). The first two aspects, environmental effectiveness and cost-efficiency, can usually be assessed through non-participatory IA. The third and fourth aspect requires a PIA, defined as "an IA approach in which social stakeholders... contribute their knowledge and policy preferences to the assessment of complex policy problems" (Schlumpf et al. 1999, p. 2). Stakeholder participation is needed because assessing practical feasibility of and support from firm managers requires taking into account stakeholder knowledge, values and perceptions, and stakeholders may also need to be consulted for the first and second aspects if information is lacking on costs and environmental effectiveness.

Regarding the third aspect, options are practically feasible if they can technically be incorporated in the production process. Achieving practical feasibility in a short time span implies that that the production process does not need to undergo drastic modification when implementing the option. Assessing practical feasibility in the context of the daily routine of firms requires detailed knowledge of firm operations, knowledge which resides with stakeholders from firms. Therefore, stakeholder participation is needed for assessing practical feasibility.

Regarding the fourth aspect, support from firm managers for options entails that they are willing to implement options voluntarily or, in the case of command-and-control policy, do not object to having to implement them. Firm managers will support those options that are, in their perception, (1) in line with firm aspirations, (2) environmentally effective so that the options are legitimate and (3) better than other options to achieve environmental goals. Support from firm management for options thus depends on their values and perceptions. Knowledge on values and perception resides with stakeholders working in firms. Therefore, stakeholder participation is needed for assessing support for options.

The design of the approach described in this paper is based on four criteria. The first two criteria follow from the foregoing discussion:

(a) Stakeholder knowledge related to the production process is used in order to assess practical feasibility of options.

(b) The values and perceptions of firm management are made explicit, with firm management assessing options in light of the firms' aspirations in order to assess their support for options.

Before stakeholders can assess the practical feasibility of and reflect on their support for options (criteria a and b), they need to have knowledge of what the options entail, including their technical potential to reduce GHG emissions and their cost-efficiency. In addition, researchers may use stakeholder knowledge to improve the information on options which is needed to make the assessment, such as costs and effects. Therefore a mutual learning process is required between stakeholders and researchers, leading to the third criterion:

(c) A learning process is created in which stakeholders gain knowledge about practical details of technology options, how environmentally effective they are and what their economic impacts are, and researchers learn from stakeholders to improve information on options, such as costs and effects. 
Finally, the fourth criterion concerns flexibility. Flexibility is required because the process needs to be adaptable to the local context, which is different for each assessment. Stakeholders will have different political, policy or practical concerns that need to be addressed and different knowledge gaps will exist on cost-efficiency, environmental effectiveness or implications of options.

(d) A flexible approach is developed that may easily be adapted to the local context.

\subsection{Outline of the approach}

The approach is based on frameworks used in policy analysis and planning (Howlett and Ramesh 1995; Findeisen and Quade 1997; Hammond et al. 1999). The assessment aims at an in-depth qualitative understanding of options that can be applied to firms, obtained through focused group discussions, rather than derived from quantitative analysis alone. Focus groups are used because small group sessions allow for interaction and learning to take place within a limited timeframe, e.g., through one-day workshops.

The approach consists of six tasks where firm management ranks GHG emission reduction options based on practical feasibility and support (Fig. 1). This is achieved through using stakeholder knowledge related to the production process and making explicit their values and perceptions (criteria a and b). Learning (criterion c) is facilitated by involving experts to supply information as requested by participants, and through interactive use of a firm-level emissions model. The approach is flexible (criterion d) in that it provides a general structure, of which elements (Tasks) may be expanded, reduced or omitted as is required by the context of the assessment. The tasks can be carried out in more or less chronological order, but iterations are possible, as illustrated by the arrows on the left side in Fig. 1. In addition to the four abovementioned criteria, the approach needs to take into account two properties specific to local climate issues. Firstly, there is often a large variation in the knowledge of stakeholders on climate change. In order to take this into account, experts play a large role in the framework to inform participants on current knowledge of the climate system and impacts and response options at the local level.

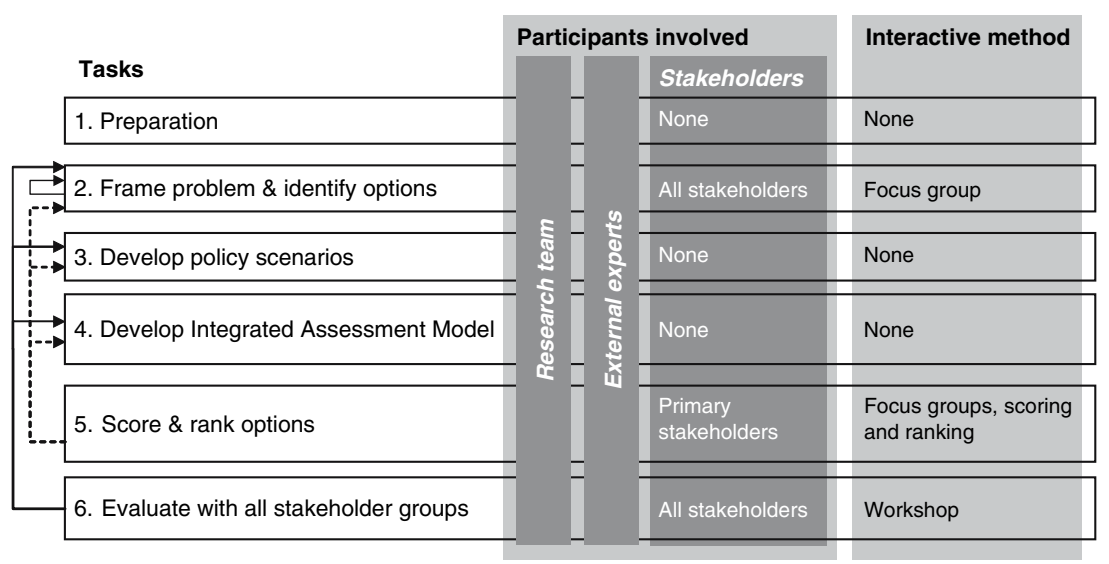

Fig. 1 An approach for Participatory Integrated Assessment 
Secondly, abatement efforts will not result in direct benefits for the firms, in terms of avoided climate impacts, because their individual contributions to global GHG emissions are negligible and because some firms are not affected by climate change. The approach therefore does not take a cost-benefit analysis approach but rather is designed to rank options in light of various possible government policies on GHG emission legislation.

The approach distinguishes between a research team, external experts, primary stakeholders and secondary stakeholders. The research team guides the assessment process and is made up of an experienced facilitator, a model builder and researchers with knowledge of the science and policy of climate change and of the sector (e.g., energy, industry, transport and agriculture). External experts are experts that are not a part of the research team and are invited ad-hoc to provide participating stakeholders and the research team with their expertise in any of the phases of the assessment. It is useful to distinguish between primary and secondary stakeholders. We define primary stakeholders as stakeholders that have direct decision making power over the issue at hand, i.e., firm management that have to implement the GHG emission reduction options. Primary stakeholders have the main focus of the PIA approach; it is their support for options and the practical feasibility in their firms that we are interested in. We define secondary stakeholders as all other stakeholders that have an influence on or are influenced by GHG emission reduction options taken by firms. Typical examples of secondary stakeholders are public decision makers, consumers and non-governmental pressure groups. The approach includes secondary stakeholders because involving them in problem framing and evaluation of the process increases the legitimacy of the PIA. Secondary stakeholders serve, in the words of Funtowicz and Ravetz, as the 'extended peer community' (Funtowicz and Ravetz 1993).

The primary and secondary stakeholders are identified in Task 1. Only primary stakeholders will participate in task 5 (scoring and ranking options) because the purpose is to determine the support for options from the perspective of primary stakeholders, and to assess practical feasibility, which requires knowledge held by primary stakeholders. All stakeholders will participate in tasks 2 (problem framing) and 6 (feed back) where engaging the extended peer community is important. The research team and external experts participate in all tasks (see Fig. 1).

\subsection{Task 1. Preparation}

The first task of the approach is the preparation of the process, where the research team defines the initial scope of the assessment, and then recruits stakeholders for participation in the assessment and engages external experts to set up a preliminary list of emission reduction options. The research team defines the initial scope of the assessment based on guidelines from the project sponsor (often a national or local government) and identifies the primary and secondary stakeholders. It may be useful to ask potential participants to name other stakeholders they think should participate (Van de Kerkhof 2004).

For our qualitative purposes, it is overambitious and not necessary to aim for a large, statistically representative number of participants. A small number of participants will suffice to identify elements that contribute to stakeholder support and practical feasibility. However, the number of participants must be large enough to take into account heterogeneity within stakeholder groups and cover the full range of perspectives of primary and secondary stakeholders. Diversity in primary stakeholders is important to enable an indepth qualitative understanding of the practical feasibility of options for and support from a 
variety of firms. Selection of primary stakeholders could cover different production processes and firm sizes. Diversity in secondary stakeholders is important to ensure that they can function as an extended peer community and review the assessment process from a variety of perspectives.

As part of the first task the research team engages external experts that are knowledgeable on the technical, scientific or policy aspects of GHG emission reduction options for the industry involved. The external experts compile a preliminary list of options which serve as a starting point for the assessment, accompanied by information on costs and environmental effectiveness if available.

\subsection{Task 2. Frame problem and identify options}

The purpose of the second task is to frame the problem with the participating stakeholders, and to identify options and criteria for assessing options through a two-stage focused group session. Using a focused group discussion allows an in-depth discussion between participants, giving room for interaction and learning, while the topics are mediated by a facilitator (Morgan 1998).

With complex problems such as climate change, where uncertainties are high and values in dispute (Funtowicz and Ravetz 1993), the problem is usually not well defined, and hence problem framing is important (Hisschemöller and Hoppe 2001; Kolkman et al. 2005). For this reason the first focus group session aims to come to a framing of the problem by discussing the climate issue, the position of primary and secondary stakeholders with respect to GHG emission reduction, and implications of climate change and GHG emission reduction options for the industry. The problem is framed interactively because how the problem is perceived will determine how it is framed (Kasemir et al. 2000). Participation of both primary and secondary stakeholders allows each to give input from their knowledge, perceptions and values so that all aspects of the problem may be considered and the legitimacy of the assessment process enhanced. Questions that can be dealt with during the first session include: What is included in the problem aside from GHG emissions? How do different stakeholder groups look at options? What are related issues? What other important developments are occurring in the industry? Where do the key uncertainties lie? How far into the future should the assessment reach?

In the second session, the options are identified interactively with stakeholders to ensure that the options correspond to the problem frame of the stakeholders and identify options specific to the firms. The discussion can start by a presentation of the preliminary list of options by the research team, which helps to make the discussion more concrete, especially for stakeholders less familiar with emission reduction options in their sector. Participating stakeholders can ask the external experts for clarification or additional information and are encouraged to give reactions to the options. The participants can then compile the list of options to be assessed, starting with a discussion of the preliminary options. Participants can add options they feel are relevant given the problem frame and the context of their firm, and discard options that they feel are not relevant. The discussion of options may result in new insights with regard to the problem frame, so that it may be useful to revisit the problem frame at this stage. With the problem frame, different stakeholder perceptions and list of options in mind, multiple criteria (such as costs, public acceptability and risk) can be identified which will serve as a basis for the assessment in task 5 .

The revised problem frame may result in a different group of stakeholders than the initial scope identified in Task 1. In this case, it may be necessary for the research team to recruit 
additional stakeholders which have a stake according to the new problem frame. These stakeholders can then participate in Tasks 5 and 6. If there is a large difference between the revised problem frame and the initial scope, it may be necessary to repeat Task 2 .

\subsection{Task 3. Develop policy scenarios}

In the third task, the research team designs three to four short policy scenarios. The purpose of the scenarios is to provide benchmarks for the ranking in Task 5 which take into account short-term developments in government policy and other, uncertain, developments.

Scenarios are images of alternative futures (Nakicenovic and Swart 2000), and are often used in IAs to investigate the possible scope of future developments (e.g., Nakicenovic and Swart 2000; Millenium Ecosystem Assessment 2003). Such scenarios are often fully fleshed-out storylines. However, because of the application to ranking, short narratives will suffice. Also, the scenarios can be incremental along the single dimension of incentive to adopt climate measures rather than along two or more dimensional axes as is often the case in IAs (e.g., Nakicenovic and Swart 2000). The scenarios are increasing in the amount of incentives they provide to reduce emissions, and they are incremental in that each scenario includes the incentives in the previous scenarios plus additional incentives.

The research team builds the scenarios based on the main issues, uncertainties and temporal scope as identified in Task 2 (problem framing). The scenarios can for example describe short-term (sectoral) developments in national climate policy and the economy in relation to GHG emissions. The number of scenarios should be limited to be practical in their application yet be enough to allow for sufficient distinction in ranking of options. Government policies can be used to vary the incentives in the scenarios. This will also allow a gauging of the reactions of primary stakeholders to different government policy by investigating their ranking of options into the scenarios. Developments with high uncertainty can also be incorporated in some scenarios, whereas developments with low uncertainty can be equal for all scenarios. External experts can be asked to give quantitative estimates of key variables related to future developments.

If Task 2 has not produced a sufficiently clear problem definition upon which to build the scenarios, participatory scenario building (Slocum 2003) may be used at this stage to further explore the problem definition interactively with stakeholders.

\subsection{Task 4. Develop an integrated assessment model}

In Task 4 the research team develops or adapts an Integrated Assessment Model, e.g., a firm-level GHG emission model, which can quantify the effects of implementing emission options in the different scenarios. The purpose of the model is to serve as a tool for learning by helping participating stakeholders to better understand the quantitative effects of options. The physical processes underlying GHG emissions can be difficult to understand, especially if many interactions exist. Although a well-validated model with low uncertainty would be preferable, the model is used here as a communication and discussion tool so that it is not essential that uncertainties are low.

The model should include reductions of GHG emissions and, if available, variables related to key issues identified in Task 1 so that participating stakeholders can investigate the effects of individual options in each scenario. One of the most important key issues will likely be costs related to options. Interactions between options, such as mutual exclu- 
siveness (cf. Dellink 2005) should also be taken into account so that cumulative effects of multiple options can be calculated. External experts can supply data on costs and emissions and information on interactions between options.

Using a model in a participatory setting puts special demands on the model. Van der Sluijs argues that the model should have an easy to use and interactive interface, be transparent and makes uncertainties and value-laden assumptions clearly visible, and allow inclusion of local knowledge (Van der Sluijs 2002). Dahinden et al. suggest that the model should also have a local, short-term focus, based on their experiences in the Urban Lifestyles, Sustainability and Integrated Environmental Assessment (ULYSSES) project (Dahinden et al. 2000). The model used in the case study presented in Sect. 3 of this paper is an example of a model that is designed to meet these demands (Van Amstel et al. 2004). Van der Sluijs also argues that the model should encourage problem structuring and "foster the creative generation and exploration of rival problem definitions, accommodating the entire spectrum of perspectives and values of the stakeholders involved" (Van der Sluijs 2002, p. 141). Problem structuring occurs in Task 1 so that there is no need for the model to facilitate this process.

\subsection{Task 5. Score and rank options with firms}

This task involves a series of scoring and ranking sessions with primary stakeholders to achieve a ranking of options according to stakeholder support and practical feasibility. The scoring facilitates making explicit the stakeholder support and practical feasibility as well as the knowledge, values and perceptions which underlie them. The ranking allows identification of the most effective options with regard to practical feasibility and stakeholder support.

The research team facilitates the scoring and ranking and the related group discussions, while external experts supply information on options. The number of scoring and ranking sessions to be held depends on the number of firms active in the sector and the number of sub-groups of firms that are relevant considering production process and GHG emissions.

When scoring, each option is dealt with in turn. An external expert introduces the option and a member of the research team instigates a short discussion to ensure that the technical details of the option are clear for all participants. The model can provide information on environmental and cost effectiveness of the option for different firm configurations such as firm size and production method. Participating stakeholders then individually score the options based on how they value the option regarding each of the criteria defined in Task 2, while keeping the situation on their own firms in mind. Scoring can be done using one of many scoring techniques (e.g., Schwarz 1995; Barbour and Kitzinger 1999; Susskind et al. 1999).

Participants should be encouraged not to discuss their scores during the scoring so that the scores reflect diversity of individual preferences. After scoring, participants discuss the advantages and disadvantages of options and explain their choice of scores. This discussion makes explicit the motivations underlying the choices of scores, in terms of values and perceptions, and the information on practical feasibility on which they base their choice.

The options are then ranked by the group using the scenarios developed in Task 3 . Participating stakeholders indicate in which scenario they would take an option. They are asked to consider the degree of incentives, represented by the scenarios, needed for them to be willing to implement each option while considering the practical feasibility and their 
support for the option. Because the scenarios are incrementally increasing in incentive, options taken in a scenario will in principle include all options in the prior lower-incentive scenarios. For mutually exclusive options participants can indicate which options from prior scenarios they choose not to adopt ${ }^{1}$. (Brink et al. 2001)The model can be used during ranking to demonstrate the effect of the combination of options taken in each scenario, for example to test whether a reduction target as set in a policy scenario is achieved.

The scoring exercise is used to facilitate discussion of the advantages and disadvantages of the options in preparation for the ranking, but decision how each option is ranked, i.e., how the scores are weighted to determine the ranking, is done implicitly by the participating stakeholders. Thus there is no formal relation between the scores and the ranks, in contrast to weighted multi-criteria analyses (Pluimers 2001). The implicit weighting suffices because it can best represent the variety of opinions in the group and because we are interested in subjective valuations of practical feasibility and support. After the scoring and ranking sessions are completed the research team can combine the rankings of the groups into an overall ranking of options, highlighting commonalties and differences between different groups and noting the aspects of practical feasibility and stakeholder support that explain the rankings.

\subsection{Task 6. Evaluate with all stakeholder groups}

The purpose of this task is to evaluate the assessment on the validity of the process, identifying knowledge gaps, and investigating policy implications. Although the assessments of Task 5 are carried out by primary stakeholders from their perspective, secondary stakeholder groups can check during Task 6 if the scope of the assessment and assessment process is valid with respect to the problem frame as arrived at in Task 2 . In addition, secondary stakeholders can help identify knowledge gaps that, from their perspective, need to be filled to make the results more valid.

To allow for interaction between representatives of primary and secondary stakeholder groups, it is suggested to include a workshop with all stakeholders in Task 6, facilitated by the research team. External experts can provide additional information at the request of participating stakeholders. The research team starts the workshop by presenting the results of the scoring and ranking sessions (Task 5), supplemented with model calculations for each scenario. The presentation is followed by a discussion on the results and an evaluation of the research process. In relation to the results, issues that may be addressed include: Are the options taken in each scenario consistent and realistic? What knowledge gaps exist? With regard to the research process, issues that can be addressed are: Does the scope of issues addressed in the assessment of options fit with the original problem framing? Have the original goals been achieved?

\subsection{Iterations}

The results of tasks 5 or 6 may give reason to revise the problem frame, models or scenarios so that iterations to Tasks 2,3 or 4 can take place. Task 2 may also result in a revised problem frame, in which case an iteration of Task 2 may be needed. The arrows in the left part of Fig. 1 represent the iterations.

\footnotetext{
1 When cost-effectiveness is the overriding criteria for the choice between mutually exclusive options, participants may be assisted by general guidelines as given in (Dellink 2005) or Brink et al. (2001)
} 


\section{PIA-agriculture case study}

Agriculture accounts for half of the Dutch methane $\left(\mathrm{CH}_{4}\right)$ and nitrous oxide $\left(\mathrm{N}_{2} \mathrm{O}\right)$ emissions, the two most important non-carbon dioxide $\left(\right.$ non- $\left.\mathrm{CO}_{2}\right)$ greenhouse gasses $\left(\right.$ Klein Goldewijk et al. 2005) ${ }^{2}$. In the Dutch national Reduction Program on non- $\mathrm{CO}_{2}$ greenhouse gasses $\left(\mathrm{ROB}^{3}\right)$ the technical potential to reduce emissions has been determined for a broad range of options, but the practical feasibility of these options and primary stakeholders' support for these options was unknown. The purpose of the PIA-agriculture case study was to assess the practical feasibility of and support for options to reduce non$\mathrm{CO}_{2}$ emissions in agricultural firms in the Netherlands (Van Amstel et al. 2004).

The case follows a preliminary version of the PIA approach described in the previous section. A main difference with the outlined approach is that the interactive discussion of options did not consider options other than the preliminary list. The preliminary list of options compiled in the ROB program was already very extensive, so stakeholders were asked which options they felt were not relevant, but not asked to think of additional options. Also, the model was only used in the final workshop and not in the scoring and ranking sessions (Task 5) because the model was not yet available at that time.

\subsection{Preparation (Task 1)}

The project team was composed of one project leader and four scientists from various disciplines. The scientists either had a systems analysis, economics or policy background in the field of environmental science. To prepare for the introductory workshop stakeholders selected and were invited using existing mailing lists ${ }^{4}$ to participate in the process, including actors from the private sector (i.e., farmers), scientists and policy makers from government agencies. The ROB research program provided a preliminary list of GHG emission reduction options for agricultural firms.

\subsection{Problem framing (Task 2)}

The first workshop was attended by a selective group of farmers, scientists and policymakers. Concerning the scope of the problem, a key conclusion was that in-depth discussion among participants from the whole Dutch agricultural sector was not possible, because of the large differences between different types of agricultural production. Therefore, the decision was made to focus on dairy farms for the rest of the project. Dairy farms are an important source of non- $\mathrm{CO}_{2}$ greenhouse gasses, accounting for

\footnotetext{
${ }^{2}$ Agriculture accounts for $49 \%$ of Dutch $\mathrm{CH}_{4}$ emissions and $56 \%$ of Dutch $\mathrm{N}_{2} \mathrm{O}$ emissions in 2003. 8.2\% (by $\mathrm{CO}_{2}$-eq) of total Dutch greenhouse gas emissions in 2003 are from the agricultural sector (Klein Goldewijk et al., 2005).

${ }^{3}$ ROB is a research and policy implementation program coordinated by the Netherlands Agency for Energy and the Environment (Novem) and aims to support national efforts to reach the Dutch Kyoto Protocol targets.

${ }^{4}$ Mailing lists were provided by the Dutch Centre for Agriculture and Environment (CLM) and through the project "Koeien \& Kansen" (Cows and Opportunities, a research project on sustainable dairy farming).
} 
Table 1 Criteria for assessing GHG reduction options as used in the case study

\begin{tabular}{ll}
\hline Criteria & Description \\
\hline $\begin{array}{l}\text { Economics } \\
\text { Manure policy }\end{array}$ & $\begin{array}{l}\text { Does the option influence the economic performance of the dairy farm? } \\
\text { Labor }\end{array}$ \\
Diet & Does the option require extra labor? \\
Raw feed & Does the option fit in the strategy of the dairy farmer regarding the diet composition? \\
Animal welfare & Does the option affect animal health and welfare? \\
Soil quality & Does the option affect soil management, quality or structure?
\end{tabular}

approximately $25 \%$ of non- $\mathrm{CO}_{2}$ GHG emissions in the Netherlands ${ }^{5}$, and most types of reduction options for the agricultural sector as a whole are also applicable to dairy farms.

The farmers and farmers' representatives at the workshop said that they are very concerned with manure policy and that options taken for manure policy also influence GHG emissions. A conclusion from the workshop was that government objectives on different types of policy, in particular manure policy to combat acidification versus climate change policy, should not oppose each other. The scope of the PIA should therefore include not only climate policy but also manure policy. The most important and uncertain driving force influencing the choice of options to be implemented was whether or not the Dutch request for a derogation of the European nitrogen $(\mathrm{N})$ directive, which would lead to a more lenient manure policy, would be accepted by the European Commission (Van Amstel et al. 2004). The European Commission had not yet reached a decision at the time of the assessment.

In the discussion, participating stakeholders concluded that farmers are only interested in taking climate emission reduction options if they gain economically. The evaluation criteria for scoring (in Task 5) should include economics. The criteria identified by participants, shown in Table 1, include criteria specific to practical feasibility.

\subsection{Develop climate and manure policy scenarios (Task 3)}

Four scenarios were developed based on the problem framing in Task 2 . The scenarios describe describing possible paths firms in the agricultural sector might follow in the coming decades in the light of manure and climate policy (see Table 2).

The four scenarios are designed to be incrementally increasing in incentives to adopt measures by increasing government pressure on implementing options. Combinations of manure and climate policy scenarios were devised because the participating stakeholders in the first workshop identified manure policy as the largest uncertainty. Thus, scenarios 1 and 2 vary only in the strictness of the manure policy and have no climate policy. Scenarios 2, 3 and 4 all adopt a strict manure policy, but show increasing incentives (or pressure) to implement GHG emission reductions.

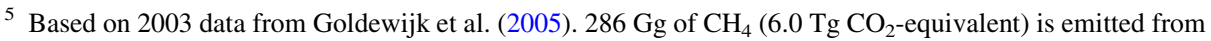
dairy farms through entric fermentation and manure management. About half of the $28.3 \mathrm{Gg} \mathrm{N}_{2} \mathrm{O}$ emitted as a result of nitrogen additions to grasslands is from dairy farms, which amounts to approximately $4.3 \mathrm{Tg}$ $\mathrm{CO}_{2}$-equivalent
} 
Table 2 PIA agriculture policy scenarios (developed in task 3 of the case study)

Scenario Key elements of storyline

1. Lenient manure policy/no climate policy

2. Strict manure policy/no climate policy

3. Strict manure policy/lenient climate policy

4. Strict manure policy/strict climate policy
The Dutch government sets no specific targets for the agricultural sector and succeeds in its request for a derogation of the European nitrogen (N) directive so that fertilization is allowed up to a maximum load of $250 \mathrm{~kg} \mathrm{~N} / \mathrm{ha}$. This is stricter than the current manure policy.

The European Union does not agree with the Dutch derogation of the Ndirective, so that the maximum fertilization load is set at $170 \mathrm{~kg} \mathrm{~N} / \mathrm{ha}$.

The manure policy is the same as in scenario 2 . The agricultural sector must reduce their GHG emissions by at least $6 \%$, and is able to sell certified emission reduction credits (CERs) at a price of $€ 20 / \mathrm{tC}$, making all reduction measures below this price profitable.

The manure policy is the same as in scenario 2. The agricultural sector must reduce their GHG emissions by $50 \%$ between 1990 and 2010.

\subsection{KLIMLAB model development (Task 4)}

A model was developed for GHG emissions at farm level, called KLIMLAB (KLImaat op het LandBouwbedrijf-Climate at the Agricultural Firm). The model aims to improve the quality of the assessment by providing quantitative information on emissions and stimulating discussion on the scientific basis of emission estimates. Figure 2 illustrates the data structure of the model.

KLIMLAB is a simple spreadsheet model. Participants can input the expected farm characteristics in 2010 given a 'business as usual' future (i.e., assuming that current manure policy is maintained). The model uses emission factors to calculate non- $\mathrm{CO}_{2} \mathrm{GHG}$ emissions from the farm in 1990 and 2000. Based on expected farm characteristics in 2010 the model calculates the emissions in 2010 if no options were taken. Participants can then input options they would take under each scenario. The model then gives emissions in 2010 for each scenario.

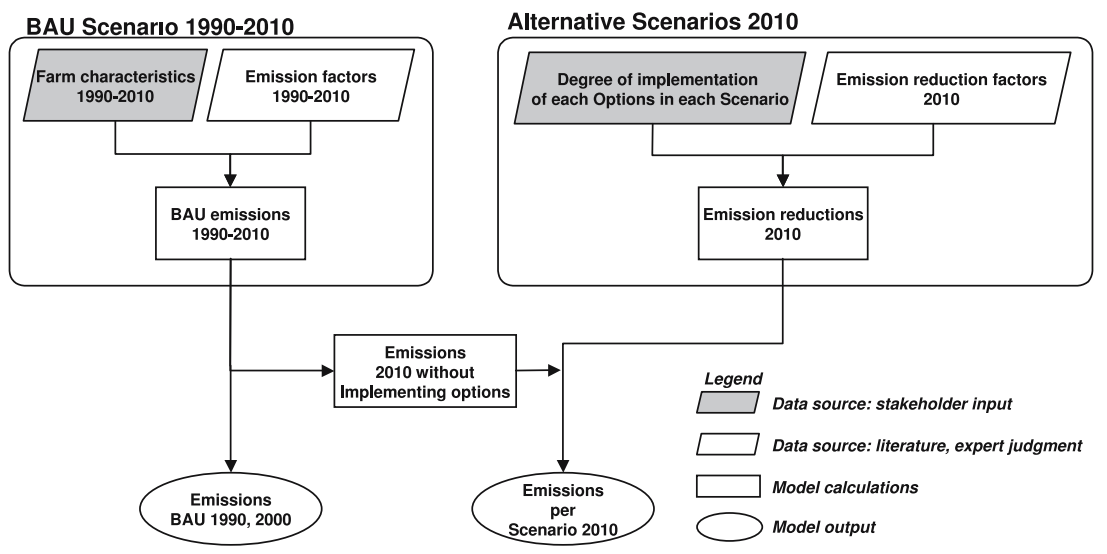

Fig. 2 KLIMLAB model data structure. BAU = Business as Usual 
KLIMLAB is designed to meet the conditions for use in participatory settings outlined in the approach (Sect. 2). The following lists how the model accommodates for these conditions:

- The model should be as transparent as possible: The KLIMLAB model is simple and intuitive, so that when properly introduced individual stakeholders can understand how the model works.

- Uncertainties should be made explicit: The largest uncertainties in the model are the emission (reduction) factors. The most important emission factors, such as $\mathrm{N}$-excretion per cow (bos taurus), are shown.

- Value-laden assumptions should be made explicit and variable: Values of future emission reduction factors are shown.

- The model should be interactive: The model runs on a desktop computer. Users can provide their own inputs and analyze the response in emissions.

- The model should allow the inclusion of local knowledge in the assessment: Participating farmers using the model make their own choice which options to take under which scenario, based on their own knowledge and values. The model does not prescribe how the choice for selecting options is made.

- The model should have a local, short-term focus: The model is at the scale of the farm corresponding to the scale at which the primary stakeholders operate.

\subsection{Scoring and ranking options (Task 5)}

Scoring and ranking sessions were held with four groups of five dairy farmers in different regions in the Netherlands. Two regions had farms on sand, one on peat and one on clay. Prior to the session, participants received a background document on options to reduce GHG emissions in dairy farms. Since the model was not yet available, an expert provided all extra information on options. Participants then individually scored the options against the evaluation criteria (Table 1) by placing stickers on a matrix drawn up on a flip-over sheet. After scoring, the dairy farmers ranked options as a group using the policy scenarios (Table 2). We gave participants the opportunity to identify potential conflicts in ranking the options, such as problems arising with mutually exclusive options. It was, however, beyond the scope of this case to resolve these issues because the objective of this case was to identify promising options that deserve more investigation, not to come up with ultimate set of best options.

Table 3 highlights some results of the scoring and ranking sessions. The table shows which options participating farmers said they would take under each scenario, and on which evaluation criteria the options scored positively or negatively. Although 24 emission reduction options were discussed in the focus groups (dairy farms on sand, clay and peat), for simplicity only those options are shown that ranked similarly in all focus groups; full results may be found in Van Amstel et al. (2004).

The results give a clear picture of the motivations of participating farmers to take GHG emission reduction options under manure or climate policy, based on the practical feasibility of the option on their farm and their support for the option. The options ranked under scenarios 1 and 2 are options which, based on the results of the focus groups, can be expected to be taken under new Dutch manure policy with or without the derogation of the European N-directive. These options, which all relate to optimal fertilizer use and increased milk production, have the most support from dairy farmers and 


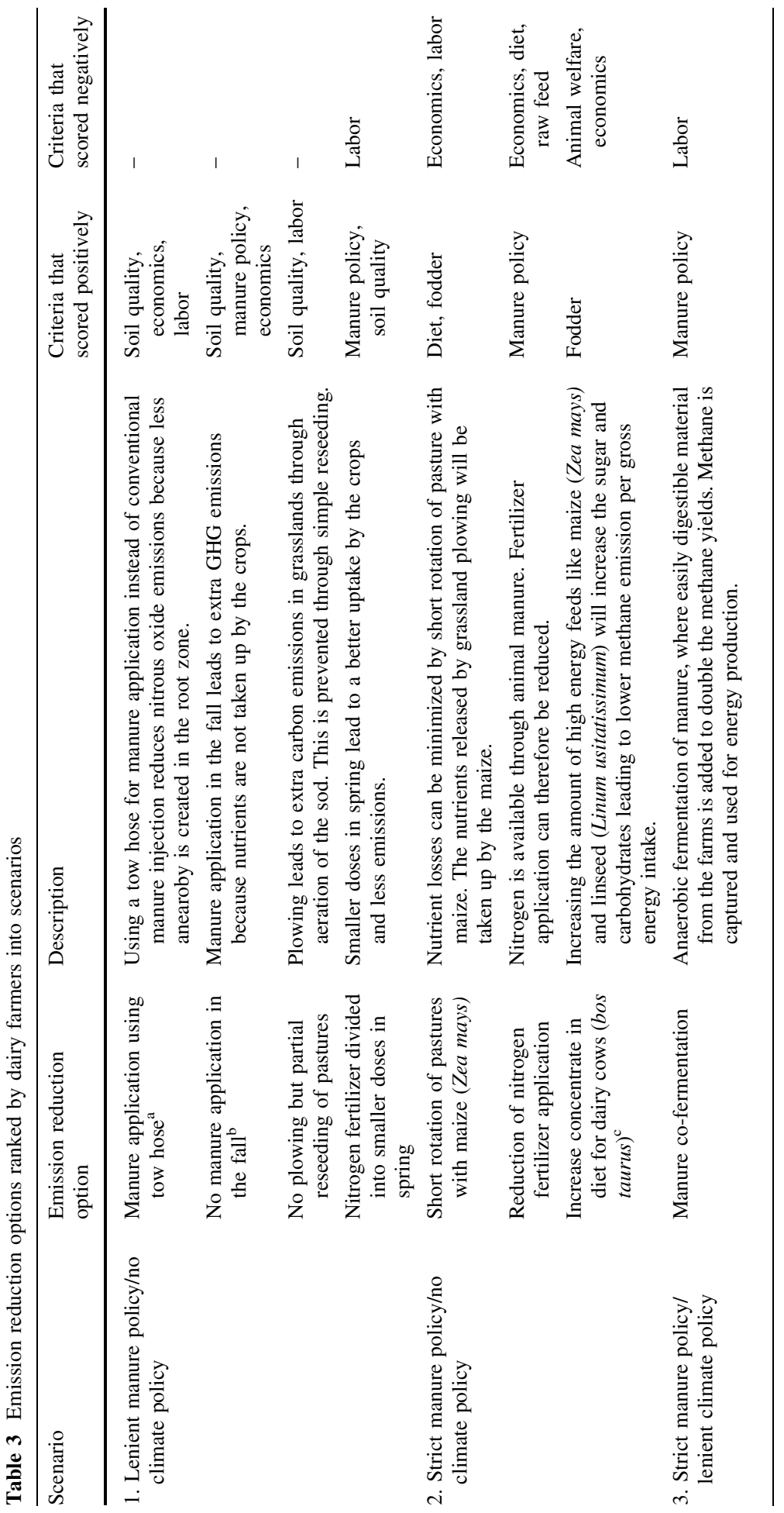




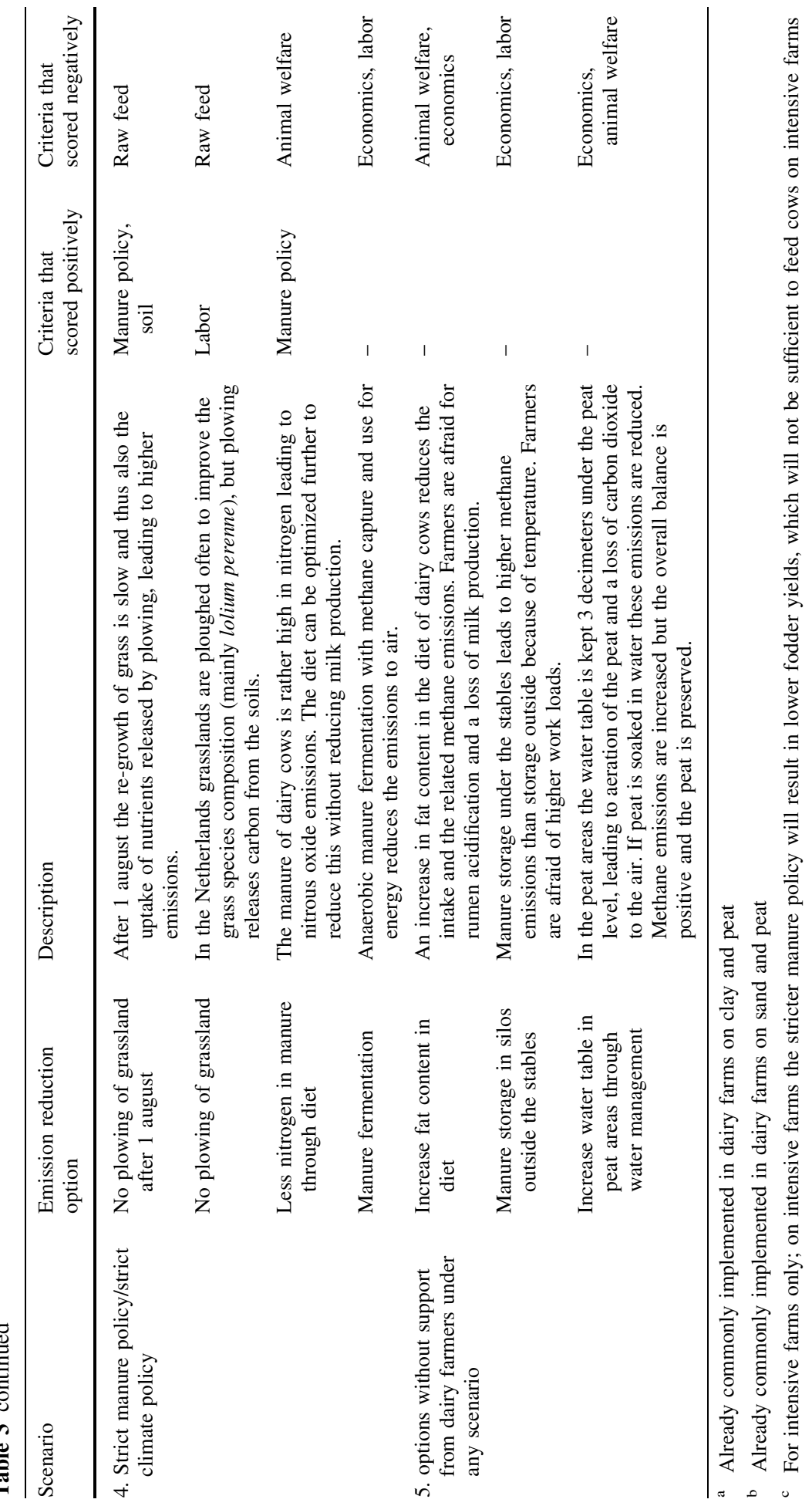


are the most practically feasible, especially those under scenario 1. 'Manure co-fermentation' is the only option ranked in scenario 3 which participating stakeholders would take in the case of lenient climate policy. This option scores negatively on economics because it requires a large investment to build the fermentation silo. Participating stakeholders felt the risk was too high given that the price of the electricity produced is not guaranteed, and because there was little field experience with co-fermentation so they were uncertain of the productivity of the technology. Furthermore, neither the required emission reduction nor the income from selling certified emission reduction credits (CERs) provide sufficient stimulus to adopt more options. Fermentation of only manure is less productive than co-fermentation and is therefore not seen by participating farmers as a viable option under the lenient climate policy scenario, but becomes viable under the strict climate policy scenario (scenario 4). The options ranked under scenario 4 are a potential focus of climate policy if emissions need to be reduced beyond the reductions already occurring as a result of manure policy. These options warrant further investigation on how the criteria on which they score negatively may be reduced. 'Scenario 5' is an extra scenario, which includes all options that will not be taken by participating farmers under any scenario. Increase of fat in cow diet results in lower methane emissions but also reduces appetite and affects milk quality. Manure storage in silos instead of in the basement under the cow sheds, which results in less methane emissions due to the lower temperature in the silos, is not supported because it requires a lot of extra labor to move the manure and there are no ancillary benefits. Dairy farmers on peat resist the raising of the groundwater level because fields become inaccessible with heavy machinery. Because these options have little support from dairy farmers and are practically infeasible, it is suggested for the ROB research program to first investigate whether these obstacles can be overcome before more resources are devoted to technical research on these options (Van Amstel et al. 2004).

\subsection{Evaluation workshop (Task 6)}

The objectives of the workshop were to reflect on the assessment made during the scoring and ranking sessions, and to have participating stakeholders learn about and identify knowledge gaps in the science underlying the options. The results of the first workshop and the scoring and ranking sessions were presented to the participants, as well as some presentations on the science behind the GHG emission estimates for the agricultural sector.

The KLIMLAB model was used in the evaluation workshop to communicate to participants the effect of options assessed in the scoring and ranking sessions, and to test the potential for using this model as a learning tool. Participating stakeholders were separated into homogenous groups of 4-5 people (dairy farmers on clay; dairy farmers on peat; dairy farmers on sand; scientists; policy makers). The homogenous composition of each group diminishes competition and allows for easy reaching of consensus (Giaoutzi 2004). Farmers were asked to fill in the farm characteristics representative of their group, and other groups could choose a default set of farm characteristics. They could then use the model to investigate the effect on GHG emissions of taking different sets of options under each policy scenario.

The workshop ended with a plenary discussion on the process followed in the assessment and on insights gained through the modeling exercises. Participants had the chance to reflect on knowledge gaps in the science underlying the options. For several options, e.g., co-fermentation, participants felt that more scientific knowledge on biochemical processes 
was needed. The model triggered a lively discussion on the state of science of options. In the evaluation survey this discussion was the highest valued element of the workshop (4.2 average on a 5-point scale).

The general conclusion from this workshop was that primary and secondary stakeholders considered the followed approached (first an introductory workshop, then scoring and ranking sessions and finally a second workshop) a good method to assess options, thereby validating the process. The KLIMLAB model was generally considered a good tool to help stakeholders understand the effect of options on GHG emissions, but the participating farmers did not yet regard the model as realistic enough because of unrealistic assumptions in the $\operatorname{model}^{6}$ and this hampered their capacity to learn from the model.

\section{Discussion and conclusions}

This paper has presented an approach that is a proposal for more systematic PIAs identifying effective public policies for short-term GHG emission reduction options in firms. The approach consists of framing the problem with all stakeholders, scoring and ranking with the primary stakeholders, and evaluation with all stakeholders.

The approach has been applied in a case study to identify effective options for non- $\mathrm{CO}_{2}$ GHG emission reductions in Dutch dairy farms. The case study successfully identified options that are both practically feasible and have the support from dairy farmers, the most promising of which were those that lead to optimized fertilizer and manure use and increased milk production of dairy cows.

The case study followed the approach but differed on two points. Firstly, the model was not available during the scoring and ranking focus group sessions (Task 5 of the approach), but the model was instead applied in Task 6 to explore the potential for using the model to communicate effects of options where it resulted a critical debate on the state of science on emission reductions. As such the case study did not fully examine the potential of using a model in the approach as a learning tool. Other studies, however, indicate that use of models in participatory focus groups can enhance understanding of GHG emissions (Dahinden et al. 2000; Schlumpf et al. 2001). Secondly, the identification of options with stakeholders only included stakeholders' rejection of options on the preliminary list compiled by experts, and stakeholders were not asked to think of other options. For the case it was chosen not to do this because the preliminary list of options was already very extensive since the ROB program had researched many options for the agricultural sector. Since the model was not used in the scoring, and the stakeholder participation in identification of options was limited, these elements of the approach need to be tested in future cases.

We argue that the case study demonstrates the main strength of the approach: it avoids a common pitfall of participatory research projects by providing balance between practical, context specific issues and scientific-theoretical aspects. Regarding practical issues, the approach is flexible enough to be adapted to the local context in which it is applied, and is designed to cope with two aspects specific to firm-level climate policy. The first aspect, the need for participating stakeholders to learn about what climate change is and what potential

\footnotetext{
${ }^{6}$ Farmers questioned the assumption of the N-excretion per cow per year (ranging from $100 \mathrm{~kg} \mathrm{~N}$ in 1990 to $150 \mathrm{~kg} \mathrm{~N}$ per cow in 2010) because farmers can influence this number, and that the estimate for 2010 was too high.
} 
options imply for their firms, is met in the approach through the use of a model and the role of experts as a source of information. The second aspect, the problem that there is no incentive for firms to mitigate GHG emissions, is met in the approach by basing the option ranking on the response of firms to government policy. Regarding scientific-theoretical aspects, the approach provides a rigorous methodology where secondary stakeholders function as the extended peer community in framing the problem and evaluating the results, and where ranking of options from the perspective of primary stakeholders is achieved in a systematic way.

This approach has been designed for firm-level climate change policy. The current approach is climate-change specific in its attention for participants' learning about climate change and in dealing with the lack of direct benefits for firms to implement options. It might, however, be possible to adapt the approach for assessments of other environmental issues.

The current approach requires more empirical testing, and can be built upon and improved in further studies, so that PIAs will become more theoretically sound and systematic, and thus be more useful for policy making. One possibility is the extension to evaluate the PIA process with respect to the actual implementation of emission reduction options. Such an improved approach may substantially contribute to the quality of environmental policies, the relevance of which is undoubted, given the high stakes involved and reluctance for voluntary action by polluters.

Acknowledgements We would like to thank the participants of the PIA-Agriculture case study for their time, Dr. Dale S. Rothman of The Macaulay Institute, Prof. Rik Leemans and Prof. Ekko van Ierland of Wageningen University and three anonymous reviewers for their helpful comments, and A. Kool and H. de Ruiter of the Centre for Agriculture and the Environment (CLM) for their assistance in the case study. This research was supported by the Netherlands Reduction Program on non- $\mathrm{CO}_{2}$ Greenhouse Gasses (ROB).

\section{References}

Barbour RS, Kitzinger J (eds) (1999) Developing focus group research: politics, theory and practice. Sage Publications, London

Behringer J, Buerki R, Fuhrer J (2000) Participatory integrated assessment of adaptation to climate change in Alpine tourism and mountain agriculture. Integr Assess 1:331-338

Brink C, van Ierland EC, Hordijk L, Kroeze C (2001) Cost-effective emission abatement in europe considering interrelations in agriculture. Scientific World 1(S2):814-821

Dahinden U, Querol C, Jäger J, Nilsson M (2000) Exploring the use of computer models in participatory integrated assessment-experiences and recommendations for further steps. Integr Assess 1(4):253266

Darier É, Jaeger CC, Kasemir B, Schüle R, Shackley S, Wynne B (1998) Contributions to participatory integrated assessment. Darmstadt University of Technology, Center for Interdisciplinary Studies in Technology, Darmstadt

Dellink RB (2005) Modelling the costs of environmental policy: a dynamic applied general equilibrium assessment. Edward Elgar Publishing, Cheltenham

Findeisen W, Quade ES (1997) The methodology of systems analysis: an introduction and overview. In: Miser HJ, Quade ES (eds) Handbook of systems analysis. volume one-Overview of uses, procedures, applications, and practice. John Wiley \& Sons, Chichester, pp 117-149

Funtowicz SO, Ravetz JR (1993) Science for the post-normal age. Futures 25(7):739-755

Giaoutzi M (2004) Paris: Personal communication at the COST A22 'Foresight Methodology' workshop, 2 April 2004

Glicken J (2000) Getting stakeholder participation 'right': a discussion of participatory processes and possible pitfalls. Environ Sci Pol 3(6):305-310

Hammond JS, Keeney RL, Raiffa H (1999) Smart choices: a practical guide to making better decisions. Harvard Business School Press, Boston, MA 
Hare M, Pahl-Wostl C (2002) Stakeholder categorisation in participatory integrated assessment processes. Integr Assess 3(1):50-62

Hedger MM, Martinot E, Onchan T (2000) Enabling environments for technology transfer. In: Metz B, Davidson OR, Martens J-W, van Rooijen SNM, van Wie-McGrory L (eds) Methodological and technological issues in technology transfer. Cambridge University Press, Cambridge, pp 105-141

Hisschemöller M, Hoppe R (2001) Coping with intractable controversies: the case for problem structuring in policy design and analysis. In: Hisschemöller M, Hoppe R, Dunn W, Ravetz J (eds) Knowledge, power, and participation in environmental policy analysis. Transaction Publishers, New Jersey, USA, pp 47-72

Howlett M, Ramesh M (1995) Studying public policy: policy cycles and policy subsystems. Oxford University Press, Toronto

Kasemir B, Dahinden U, Swartling AG, Schule R, Tabara D, Jaeger CC (2000) 'Citizens' perspectives on climate change and energy use. Glob Environ Change 10(3):169-184

Klein Goldewijk, K, Olivier JGJ, Peters JAHW, Coenen PWHG, Vreuls HHJ (2005) Greenhouse gas emissions in the Netherlands 1990-2003. National Inventory Report 2005, RIVM

Kolkman MJ, Kok M, van der Veen A (2005) Mental model mapping as a new tool to analyse the use of information in decision-making in integrated water management. Phys Chem Earth Parts A/B/C 30(45):317-332

Lin E, Cerri CC, Frisvold G, Minami K, Doering O, Sampson N, Waggoner P, Plucknet D, Neue HU, Makarim K, Hubbard K, Jiusheng L, Yu'e L, Ruttan V (2000) Agricultural sector. In: Metz B, Davidson OR, Martens J-W, van Rooijen SNM, van Wie-McGrory L (eds) Methodological and technological issues in technology transfer. Cambridge University Press, Cambridge, pp 269-289

Millenium Ecosystem Assessment (2003) Ecosystems and human well-being: a framework for assessment. Island Press, Washington, D.C

Morgan DL (1998) The focus group guidebook. SAGE Publications Inc, California

Nakicenovic N, Swart R (eds) (2000) Special Report on Emissions Scenarios. Intergovernmental Panel on Climate Change (IPCC)

Pahl-Wostl C, Hare M (2004) Processes of social learning in integrated resources management. J Comm Appl Soc Psychol 14:193-206

Pluimers J (2001) An environmental systems analysis of greenhouse horticulture in the Netherlands. Wageningen University, Wageningen

Rotmans J (1998) Methods for IA: the challenges and opportunities ahead. Environ Model Assess 3(3):155179

Rotmans J, van Asselt M, Anastasi C, Greeuw S, Mellors J, Peters S, Rothman D, Rijkens N (2000) Visions for a sustainable Europe. Futures 32(2000):809-831

Schlumpf C, Behringer J, Dürrenberger G, Pahl-Wostl C (1999) The personal $\mathrm{CO}_{2}$-calculator: a modeling tool for participatory integrated assessment methods. Environ Model Assess 4(1):1-12

Schlumpf C, Pahl-Wostl C, Schönborn A, Jaeger CC, Imboden D (2001) Impacts-An information tool for citizens to assess impacts of climate change from a regional perspective. Clim Change 51(2):199-241

Schröter D, Polsky C, Patt A (2005) Assessing vulnerabilities to the effects of global change: an eight step approach. Mitig Adapt Strat Glob Change 10(4):573-595

Schwarz R (1995) The skilled facilitator: practical wisdom for developing effective groups. Jossey-Bass Inc, San-Fansisco, USA

Slocum N (2003) Participatory methods toolkit. A practicioner's manual. King Baudouin Foundation

Susskind L, McKearnan S, Thomas-Larmer J (eds) (1999) The consensus building handbook: a comprehensive guide to reaching agreement. Sage Publications, Thousand Oaks, California, USA

Tansey J, Carmichael J, Van Wynsberghe R, Robinson J (2002) The future is not what it used to be: participatory integrated assessment in the Georgia Basin. Glob Environ Change 12(2):97-104

Tuinstra W, Berk M, Hisschemöller M, Hordijk L, Metz B, Mol APJ (2002) Climate options for the longterm (COOL) - Synthesis report. Wageningen University, Wageningen, the Netherlands

Van Amstel A, Dellink R, Mulder I, Stalpers S, Werners S (2004) Klimaat op het LandbouwbedrijfParticipatieve Integrated Assessment (PIA) van emissiereducties van broeikasgassen in de landbouw. Wageningen University and Research Centre, Wageningen

Van Asselt MBA, Rijkens-Klomp N (2002) A look in the mirror: reflection on participation in Integrated Assessment from a methodological perspective. Glob Environ Change 12(3):167-184

Van de Kerkhof M (2004) Debating climate change: a study of stakeholder participation in an integrated assessment of long-term climate policy in the Netherlands. Lemma Publishers, Utrecht, The Netherlands

Van der Sluijs JP (2002) A way out of the credibility crisis of models used in integrated environmental assessment. Futures 34:133-146 